\title{
3 Research Square

\section{Structured psychiatric diagnoses and self-rated symptoms in primary care patients on sick leave for common mental disorders: a clinical study}

Sandra Inger Christina af Winklerfelt Hammarberg ( $\nabla$ sandra.af.winklerfelt.hammarberg@ki.se )

Karolinska Institutet https://orcid.org/0000-0001-5873-1568

Jeanette Westman

Karolinska Institutet

Dominique Hange

Goteborgs universitet Sahlgrenska Akademin

Anna Finnes

Karolinska Institutet

Cecilia Björkelund

Goteborgs universitet Sahlgrenska Akademin

Jonas Hällgren

Karolinska Institutet

Ingmarie Skoglund

Goteborgs universitet Sahlgrenska Akademin

Anna Nager

Karolinska Institutet

Research article

Keywords: adjustment disorder, anxiety disorders, clinical decision-making, depression, diagnosis, differential, primary health care, sick leave

Posted Date: December 4th, 2019

DOI: https://doi.org/10.21203/rs.2.18075/v1

License: (c) (i) This work is licensed under a Creative Commons Attribution 4.0 International License.

Read Full License 


\section{Abstract}

Background: To improve the quality of health care provided to primary care patients with mental disorders, it is crucial to understand more about the mental symptoms that underlie diagnoses on sick leave certificates.

This study therefore aimed to: 1) investigate whether diagnoses on sick leave certificates corresponded to the results of a structured psychiatric interview and to self-rated symptom severity and 2) investigate the association between length of sick leave and the diagnoses on sick leave certificates, the diagnoses made in structured psychiatric interviews, and self-rated symptom severity.

Methods: The study used data from 480 patients in SAFARI, a study on sick leave in patients with common mental disorders. At baseline, background variables were gathered and structured psychiatric interviews (M.I.N.I.) were performed. Severity of depression and adjustment disorder was assessed via self-rating scales. Data on sick leave were gathered at baseline and at 12 months from the Swedish Social Insurance Agency and patients' medical records.

Results: The diagnostic criteria for depression were fulfilled by a total of $76 \%$ of patients with a sick-leave diagnosis of adjustment disorder, $67 \%$ with a sick-leave diagnosis of anxiety, and $65 \%$ with a sick-leave diagnosis of depression $(p=0.04)$. There was no significant difference in mean net sick leave days between those with a sick-leave certificate diagnosis of adjustment disorder (mean days 119.9), anxiety disorder (107.2), or depression (137.1). However, those with depression diagnosed via structured interview had a shorter mean net sick leave (112.3) than those who did not fulfil the depression criteria (155.9). Symptom severity was strongly associated with net sick leave days; those who rated their depression or adjustment disorder symptoms as more severe had longer net sick leave.

Conclusions: Many patients with sick-leave certificate diagnoses of adjustment and anxiety disorders have ongoing depression. Longer sick leave duration was observed in those with adjustment disorder and more severe self-reported symptoms, both of which are appropriate according to Swedish guidelines.

\section{Background}

Sick leave for mental disorders is a growing problem in Sweden and many other countries (1-5). Depression, anxiety, and stress-related adjustment disorders, sometimes referred to as common mental disorders, are the major cause of sick leave in Sweden $(6,7)$. Long-term sick leave is associated with a high risk of financial stress, social isolation, and comorbidity, as well as high costs for societies and social welfare systems $(7,8)$.

Primary health care is the first line of care across the world (9), and studies estimate that between $17 \%$ and $30 \%$ of patients seeking help in primary care have mental health disorders $(4,10-13)$. In Sweden, 
general practitioners (GPs) commonly initiate sick leave certification for mental disorders. The GP writes a sick leave certificate that includes a main diagnosis, a description of the patient's functional impairment, and a recommended length and degree (percentage of full-time work: $25 \%, 50 \%, 75 \%$, or $100 \%$ ) of sick leave. An administrator at the Swedish Social Insurance Agency assesses and approves or disapproves the recommended sick leave (14).

Research shows that sick leave can facilitate the recovery of people with common mental disorders such as severe depression or stress-induced exhaustion disorder $(4,15)$. However, it can be unhelpful or even harmful for people with mental disorders such as social anxiety and phobias $(16,17)$. The correct diagnosis helps ensure that patients receive the appropriate treatment and the appropriate length and degree of sick leave. It is thus crucial to investigate the association between mental symptoms and the psychiatric diagnoses on sick leave certificates.

Methods used in primary care to diagnose mental disorders, their comorbidity, and their severity are not standardized, and as a consequence, the diagnostic procedure may vary widely between clinics and between practitioners (18-20). According to a meta-analysis of studies from primary care (21), the inclusion of a structured psychiatric interview (M.I.N.I. Neuropsychiatric Interview) (22) in the clinical assessment of mental disorders can increase the accuracy of differential diagnoses. M.I.N.I. increases both the sensitivity and the specificity of differential diagnoses (21). Taking depression as an example, clinical assessment alone detects approximately $50 \%$ of all cases, a number that rises to $90 \%$ when M.I.N.I. is included in the assessment (21). However, M.I.N.I. does not assess the severity of disorders. Instead, this is typically assessed with additional symptom rating scales and/or measures of functional impairment (23).

Previous studies show that sociodemographic factors such as sex, educational level, and socioeconomic status $(5,6,15,24-28)$ correlate with the length of sick leave. Moreover, research shows that common mental disorders are a risk factor for sick leave, both sick leave for mental and for somatic disorders $(2,8$, 29-32). Studies that examine which factors influence the length of sick leave in patients with common mental disorders differ widely in methodology and focus. In summary, some have found an association between specific psychiatric diagnoses such as depression (33) and anxiety (1) and long-term sick leave. Others have found that the severity of symptoms of anxiety and distress is the most important factor associated with longer sick leave $(1,16,29,34,35)$. This study provides an opportunity to examine the results of independent structured psychiatric interviews and self-rated symptom severity assessments in a population of patients on sick leave for common mental disorders. 


\section{Aims}

This study had two aims. The first was to investigate whether diagnoses on sick leave certificates corresponded to the results of a structured psychiatric interview and to self-rated symptom severity. The second was to investigate the association between length of sick leave and the diagnoses on sick leave certificates, the diagnoses made in structured psychiatric interviews, and self-rated symptom severity.

\section{Methods}

The data in this study were gathered between 2012 and 2017 in the SAFARI project, which has been described in detail elsewhere (36-38). Briefly, SAFARI investigated sick leave in people with common mental disorders. The current study included SAFARI data collected for two substudies: an RCT in the region of Stockholm (37) and an observational study in the region of Västra Götaland (38). These two regions include rural and urban areas and areas of varying socioeconomic status.

\section{Study population}

Our analyses included data from 300 patients from the region of Stockholm and 180 from the region of Västra Götaland. Figure 1 shows the recruitment of participants to the two substudies.

Figure 1. Recruitment of the two substudy populations

Data used in the current study were collected between 2013 and 2016. In the region of Stockholm, participants were recruited from registers at the Swedish Social Insurance Agency and via advertisements in the press. In the region of Västra Götaland, participants were recruited at 28 primary health care centers. Inclusion and exclusion criteria are shown in Table 1. 
Table 1. Inclusion and exclusion criteria in the SAFARI study

\section{Inclusion criteria}

Depression, anxiety disorders, and adjustment disorder (ICD-codes F32, F33,

F34, F38, F39, F41, F43, F48, or F99)

Age 18-60 years

Employed $\geq 20$ hours/week

Sick leave $>2$ weeks and $<12$ months

Provided written informed consent

\section{Exclusion criteria}

Severe mental disorders, including bipolar disorder, psychosis, severe depression (MADRS-S $\geq 35$ ), and ${ }^{1}$ generalized anxiety disorder

${ }^{2}$ Ongoing psychotherapy

Increased suicide risk

Substance use disorder

Inability to speak or read Swedish

Abbreviation: ICD, International Classification of Diseases; MADRS-S, Montgomery-Asberg Depression Rating Scale - self-rating version

${ }^{1}$ Generalized anxiety disorder was an exclusion criteria only in the region of Västra Götaland. No other anxiety disorders were exclusion criteria in either the region of Stockholm or the region of Västra Götaland.

${ }^{2}$ Ongoing psychotherapy was an exclusion criteria only in the region of Stockholm.

\section{Data collection}

Data collection is described in greater detail in previous publications (36-38). In summary, background variables and responses to self-rated symptom severity scales were gathered at baseline. Structured psychiatric interviews were performed by specially trained health care personnel. Baseline assessments occurred between 14 days and 3 months after the physician completed the sick-leave certificate. Data on length and degree (percentage of full-time work) of sick leave were collected at 12 months.

\section{Variables and instruments}

Background variables included self-reported data on employment status, marital status, and level of education.

Treatment data. In both regions, data on prescriptions for antidepressants were gathered via self-report. In the region of Västra Götaland, prescription data were also gathered from patients' medical records. In the region of Stockholm, treatment also included psychotherapy (acceptance and commitment therapy or ACT) and work interventions, which were part of the RCT. 
Sick leave data, including sick-leave certificate diagnoses, were gathered from the Swedish Social Insurance Agency's register for participants in the region of Stockholm. For participants in the region of Västra Götaland, these data were obtained from patients' medical records. In Sweden, sick-leave certificate diagnoses are classified in accordance with the International Classification of Diseases, $10^{\text {th }}$ edition (ICD-10) (39). We sorted sick-leave certificate diagnoses into three groups for the analyses: adjustment disorder (ICD-10 F43.8), anxiety disorders (ICD-10 F40, F41), and depression (ICD-10 F32, F33, and F34). In both regions, sick leave data also included number of days on sick leave and degree (percentage of full-time work) of sick leave. Net sick leave days were calculated by converting part-time sick leave into whole days.

Adjustment disorder, also referred to as stress-related exhaustion disorder or clinical burnout, was assessed with an instrument developed in Sweden by the Institute for Stress Medicine at the University of Gothenburg, the Self-rated Stress-Related Exhaustion Disorder Instrument (s-ED) (in Swedish, s-UMS). The instrument uses ICD-10 criteria F43.8, other specified reactions to severe stress (35).

M.I.N.I. psychiatric diagnoses. Anxiety disorders, depression, and eating disorders, as well as disorders that resulted in exclusion from the study (including bipolar disorder, psychosis, and substance use disorder) were obtained via the M.I.N.I. International Neuropsychiatric Interview 6.0 (22) in both regions. M.I.N.I. 6.0 uses the Diagnostic and Statistical Manual of Mental Disorders, $4^{\text {th }}$ edition (DSM-IV) criteria for mental disorders (40).

Depression severity was followed up with the Montgomery-Asberg Depression Rating Scale - self-rating version (MADRS-S) (41), which assesses the severity of depressive symptoms (41).

Adjustment disorder severity was measured with the Karolinska Exhaustion Disorder Scale (KEDS), developed at Karolinska Institutet, Stockholm $(42,43)$.

\section{Statistical analyses}

Continuous variables were described with mean, median, and standard deviation. Categorical variables were described using numbers and percentages. Comparisons between groups were performed using student's t-tests for continuous variables and chi-square tests for categorical variables.

Regression analysis was used to determine factors associated with the number of net sick-leave days per year while controlling for confounding. The variable "net sick-leave days" per year was analyzed as a count outcome. To account for model overdispersion, i.e., greater variability than would be expected from a Poisson distribution, negative binomial regression models (44) were used to estimate sick-leave rate ratios (RRs) with 95\% confidence intervals. All models were adjusted for age, sex, education, and 
treatment (antidepressants, psychotherapy, and/or work interventions). Statistical tests were two-tailed, and $p$-values $<0.05$ were considered statistically significant. Analyses were carried out with SAS 9.4 (SAS Institute, Inc.).

\section{Results}

A total of 480 participants were included in this study, 300 from the region of Stockholm and 180 from the region of Västra Götaland. Baseline characteristics of the participants in the two regions are shown in Table 2. There were no statistically significant differences between the regions in type of psychiatric diagnoses on sick-leave certificates, severity of depression, or severity of adjustment disorder. Significant differences in age and educational level were observed between the two regions. Participants from the region of Stockholm were 3 years older on average than those from the region of Västra Götaland $(p<0.001) ; 60 \%$ in the region of Stockholm and $44 \%$ in the region of Västra Götaland had a university education $(p<0.009)$. At the 3-month follow-up, 33\% from the region of Stockholm were treated with antidepressants, whereas $50 \%$ from the region of Västra Götaland had such treatment $(p<0.001)$. Women were in the majority in both regions $(76 \%$ in the region of Stockholm and $81 \%$ in the region of Västra Götaland). 
Table 2. The study populations from the regions of Stockholm and Västra Götaland in the SAFARI Study

\begin{tabular}{|c|c|c|c|}
\hline & $\begin{array}{l}\text { Stockholm } \\
n=300\end{array}$ & Västra Götaland n=180 & $p$ \\
\hline Age - Mean(SD) & $46(8.65)$ & $43(9.94)$ & $<0.001$ \\
\hline Female gender, $\mathrm{n}(\%)$ & $229(76)$ & $145(81)$ & 0.280 \\
\hline Education, $\mathrm{n}(\%)$ & & & 0.009 \\
\hline University & $179(60)$ & $80(44)$ & \\
\hline High school/Upper secondary school & $61(20)$ & $55(31)$ & \\
\hline Elementary school & $11(4)$ & $6(3)$ & \\
\hline Vocational training & $49(16)$ & $39(22)$ & \\
\hline Diagnosis on sick leave certificate, $n(\%)$ & & & 0.174 \\
\hline Depression & $94(31)$ & $63(35)$ & \\
\hline Anxiety disorder & $29(10)$ & $25(14)$ & \\
\hline Adjustment disorder & $177(59)$ & $92(51)$ & \\
\hline Treatment ACT/Work intervention, $\mathrm{n}(\%)$ & $225(75)$ & $0(0)$ & \\
\hline Treatment 3 months anti-depressants, n(\%) & $99(33)$ & $90(50)$ & $<0.001$ \\
\hline Treatment 6 months anti-depressants, n(\%) & $119(40)$ & $89(49)$ & 0.036 \\
\hline$s-E D, n(\%)$ & & & 0.384 \\
\hline Significant & $201(67)$ & $111(63)$ & \\
\hline No/Some & 99 (33) & $65(37)$ & \\
\hline Missing & & 4 & \\
\hline MADRS-S mean(SD) & $21.09(7.79)$ & $20.53(8.02)$ & 0.458 \\
\hline KEDS mean(SD) & $28.77(7.56)$ & $27.44(9.03)$ & 0.085 \\
\hline
\end{tabular}

Table 3 shows the association between the sick-leave certificate diagnoses and the psychiatric diagnoses received after the structured psychiatric interview (M.I.N.I.). The psychiatric diagnoses (M.I.N.I.) differed significantly between the three sick-leave certificate diagnosis groups (adjustment disorder, anxiety, and 
depression). There were significant differences in the number of diagnoses and the percentage diagnosed with panic disorder, agoraphobia, post-traumatic stress disorder, and bulimia. A total of $65 \%$ of the people on sick leave for depression met the criteria for ongoing depression according to M.I.N.I., whereas a higher percentage of those on sick leave for adjustment disorder $(76 \%)$ and those on sick leave for anxiety $(67 \%)$ did so $(p=0.041)$. There were no significant differences between the three diagnosis groups in history of depression, recurrent depression, or generalized anxiety disorder. 
Table 3. Psychiatric sick leave diagnoses by depression severity, adjustment disorder severity, and M.I.N.I. structured psychiatric diagnoses

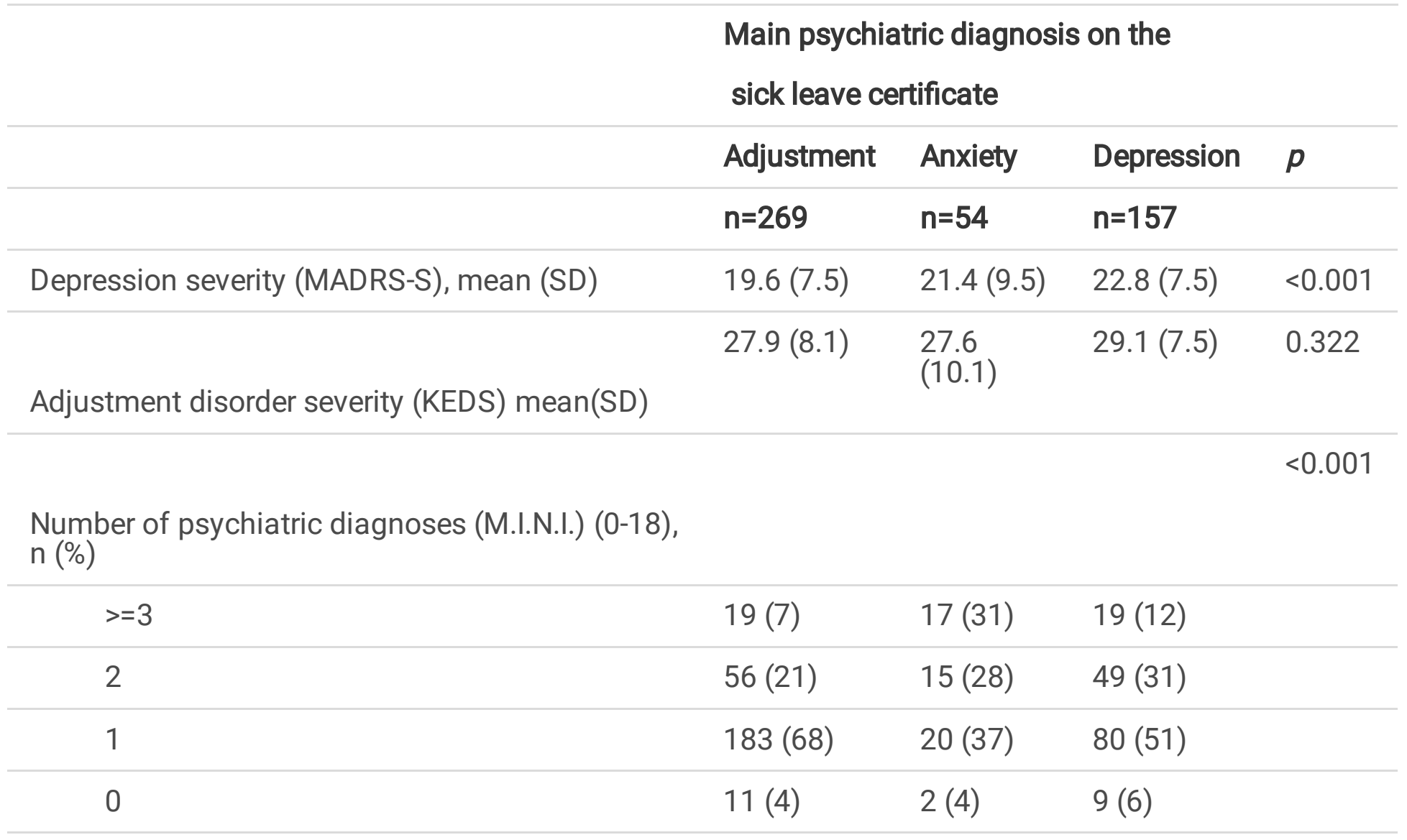

Fulfills M.I.N.I. criteria for

Ongoing depression, $\mathrm{n}(\%)$

0.041

$\begin{array}{llll}\text { No } & 64(24) & 17(33) & 55(35) \\ \text { Yes } & 199(76) & 34(67) & 100(65) \\ \text { Response missing } & 6 & 3 & 2\end{array}$

Previous depression, $\mathrm{n}(\%)$

0.330

$\begin{array}{llll}\text { No } & 148(58) & 34(67) & 95(64) \\ \text { Yes } & 108(42) & 17(33) & 54(36) \\ \text { Response missing } & 13 & 3 & 8\end{array}$

Recurrent depression, n (\%)

0.544

$\begin{array}{llll}\text { No } & 77(30) & 18(35) & 52(34) \\ \text { Yes } & 184(70) & 33(65) & 101(66) \\ \text { Response missing } & 8 & 3 & 4\end{array}$


Panic disorder, $\mathrm{n}(\%)$

$<0.001$

\begin{tabular}{|c|c|c|c|c|}
\hline Previously & $45(17)$ & $13(24)$ & $30(19)$ & \\
\hline Ongoing & $32(12)$ & $22(41)$ & $33(21)$ & \\
\hline No & $192(71)$ & $19(35)$ & $94(60)$ & \\
\hline Agoraphobia, n (\%) & & & & $<0.001$ \\
\hline Ongoing & $23(9)$ & $21(39)$ & $24(15)$ & \\
\hline No & $245(91)$ & $33(61)$ & $132(85)$ & \\
\hline Response missing & 1 & & 1 & \\
\hline Obsessive compulsive disorder, n (\%) & & & & -- \\
\hline Ongoing & $3(1)$ & $1(2)$ & $3(2)$ & \\
\hline No & $266(99)$ & $52(98)$ & $154(98)$ & \\
\hline Response missing & & 1 & & \\
\hline Generalized anxiety disorder, $\mathrm{n}(\%)$ & & & & 0.138 \\
\hline Ongoing & $39(15)$ & $12(23)$ & $33(21)$ & \\
\hline No & $229(85)$ & $41(77)$ & $124(79)$ & \\
\hline Response missing & 1 & 1 & & \\
\hline Post-traumatic stress disorder, n (\%) & & & & 0.018 \\
\hline Ongoing & $10(4)$ & $7(13)$ & $13(8)$ & \\
\hline No & $259(96)$ & $47(87)$ & $144(92)$ & \\
\hline Bulimia, n (\%) & & & & -- \\
\hline Ongoing & $0(0)$ & $0(0)$ & $4(3)$ & \\
\hline No & $269(100)$ & $54(100)$ & $153(97)$ & \\
\hline
\end{tabular}

Abbreviations: KEDS, Karolinska Exhaustion Disorder Scale; MADRS-S, Montgomery-Asberg Depression Rating Scale - self-rating version; M.I.N.I., M.I.N.I. International Neuropsychiatric Interview

The analysis of the association between mean symptom severity scale scores and the three sick leave certificate diagnosis groups (data not shown) showed that the severity of the current depressive episode differed across the three groups $(p<0.001)$. Those with a diagnosis of depression on their sick leave certificate had a mean MADRS-S score of 22.8 (SD 7.5), those with a diagnosis of anxiety disorder had a mean score of 21.4 (SD 9.5), and those with a diagnosis of adjustment disorder had a mean score of 19.6 (SD 7.5). The mean severity scores for adjustment disorders (KEDS scores) did not differ between 
the three diagnostic groups (adjustment disorder: 27.9, SD 8.1; anxiety disorder, 27.6, SD 10.1; depression, $29.1, \operatorname{SD} 7.5)(p=0.322)$.

Table 4 shows the association between mean net sick leave days and sick-leave certificate diagnoses, as well as mean net sick leave days and diagnoses made in the structured psychiatric interviews. There was no significant difference in mean net sick leave days between those with a sick-leave certificate diagnosis of adjustment disorder (mean net sick leave days, 119.9), anxiety disorder (107.2), or depression (137.1) (Model 1). Those who fulfilled the criteria for adjustment disorder as measured by s-ED had significantly more net sick leave days than those who did not (144.4 vs. 84.4) (Model 2). Those who fulfilled the criteria for ongoing depression according to M.I.N.I. had significantly fewer net sick leave days than those who did not fulfill these criteria (112.3 vs. 155.9) (Model 3). Adjusting for age, sex, level of education, and treatment did not change the pattern of the results; crude and adjusted rate ratios (RRs) are shown in Table 4. 
Table 4. Association between mean net sick leave days and psychiatric diagnoses

\begin{tabular}{|c|c|c|c|c|c|}
\hline $\begin{array}{l}\text { Crude } \\
\text { RR ( } 95 \% \\
\text { Cl) }\end{array}$ & $p$ & $\begin{array}{l}\text { Adjusted } 11 \\
\text { RR }(95 \% \\
\mathrm{Cl})\end{array}$ & $p$ & $\mathbf{n}$ & $\begin{array}{l}\text { Mean } \\
\text { net } \\
\text { sick } \\
\text { leave } \\
\text { days }\end{array}$ \\
\hline
\end{tabular}

Model 1: Main psychiatric diagnosis

on the sick leave certificate

\begin{tabular}{|c|c|c|c|c|c|c|}
\hline Adjustment disorder & $\begin{array}{l}0.87 \\
(0.69- \\
1.11)\end{array}$ & 0.276 & $\begin{array}{l}0.96 \\
(0.74- \\
1.24)\end{array}$ & 0.748 & 269 & 119.9 \\
\hline Anxiety disorder & $\begin{array}{l}0.78 \\
(0.54- \\
1.14)\end{array}$ & 0.204 & $\begin{array}{l}0.79 \\
(0.54- \\
1.15)\end{array}$ & 0.223 & 54 & 107.2 \\
\hline Depression & Ref & & Ref & & 157 & 137.1 \\
\hline
\end{tabular}

Model 2: Fulfills criteria for adjustment disorder as measured by s-ED

\begin{tabular}{lllllll} 
Yes & 1.71 & $<.001$ & 1.72 & $<.001$ & 312 & 144.4 \\
& $(1.36-$ & & $(1.37-$ & & & \\
& $2.15)$ & & $2.16)$ & & & \\
\hline No & Ref & & Ref & & 164 & 84.4
\end{tabular}

Model 3: Fulfills criteria for ongoing depression as measured by M.I.N.I.

\begin{tabular}{cllllll}
\hline No & 1.39 & 0.008 & 1.34 & 0.023 & 136 & 155.9 \\
& $(1.09-$ & & $(1.04-$ & & & \\
Yes & $1.77)$ & & $1.72)$ & & & \\
\hline Ref & & Ref & & 333 & 112.3
\end{tabular}

Abbreviations: GAD, generalized anxiety disorder; M.I.N.I., MINI International Neuropsychiatric Interview; RR, rate ratio; s-ED, Self-rated Stress-Related Exhaustion Disorder Instrument

${ }^{1}$ Adjusted for age, sex, level of education, and treatment (antidepressants, psychotherapy, and/or work interventions).

${ }^{2}$ According to s-ED and M.I.N.I. 
Figure 2 shows the association between mean net sick leave days and severity of depression symptoms (2a) and severity of adjustment disorder (2b). The more severe the symptoms, the longer the sick leave. For example, net sick leave days ranged between a mean of 65.4 days for those with adjustment disorder severity scores (KEDS scores) of $<20$ to a mean of 235.9 days for those with scores between 40 and 54 .

Abbreviations: MADRS-S, Montgomery-Asberg Depression Rating Scale - self-rating version

Abbreviations: KEDS, Karolinska Exhaustion Disorder Scale

\section{Discussion}

\section{Summary of results}

Many patients with sick-leave certificate diagnoses of adjustment and anxiety disorders had ongoing depression. The diagnostic criteria for depression were fulfilled by $76 \%$ of patients with a sick-leave diagnosis of adjustment disorder, $67 \%$ with a sick-leave diagnosis of anxiety, and $65 \%$ with a sick-leave diagnosis of depression. Sick-leave certificate diagnoses of anxiety disorders seemed to be associated with diagnoses of anxiety disorders made in the structured psychiatric interviews (M.I.N.I). There was no significant difference in net sick-leave days between people with sick-leave certificate diagnoses of adjustment disorder, anxiety, or depression. Depression diagnoses made in the structured psychiatric interviews were associated with shorter net sick leave than adjustment disorder diagnoses made in the interviews. High scores on either the MADRS-S or the KEDS symptom severity scale were associated with longer net sick leave.

\section{Comparison of current study results with those of previous studies}

The overlapping, dynamic, and sometimes chronic nature $(12,17,32,45-48)$ of common mental disorders seen in primary care patients may underlie several of the findings of the current study. Comorbidity could help explain why depression was found in so many patients on sick leave for adjustment and anxiety disorders. It could also help explain why previous depression, recurrent depression, and generalized anxiety disorder were found in similar levels in all three groups (those with sick leave certification for adjustment disorder, anxiety disorder, or depression). 
The dynamic nature of common mental disorders may also have contributed to the relatively low number of patients on sick leave for depression who had ongoing depression according to the structured interview. Perhaps some patients had recovered from their depression by the time of the structured interview, which took place 14 days to 3 months after patients received sick leave certificates. The delay between sick-leave certification and the interviews may also help explain why large numbers of the patients on sick leave for adjustment and anxiety disorders had ongoing depression according to the interview. Patients on sick leave for these disorders might have developed depression during the interval between certification and the structured psychiatric interview. Sick leave itself is a risk factor for depression $(2,15)$, especially in people with anxiety disorders $(2,8,17)$. Burnout also predicts depressive symptoms (49).

The infrequent use of structured psychiatric interviews for mental disorders in primary care $(18,19,21,47$, 50) could also help explain the differences we observed between the diagnoses on sick leave certificates and the diagnoses made in the structured interviews. A previous review found that clinical assessment alone detects approximately half of all cases of depression, a number that rises to $90 \%$ when a structured psychiatric interview (M.I.N.I.) is added to the diagnostic procedure $(21,51)$. A study in primary care has found that in the absence of a structured psychiatric interview, some mental disorders (e.g., bulimia, obsessive-compulsive disorder) can go undetected or be mistaken for other disorders with similar clinical presentations (51).

Although diagnoses on sick leave certificates are supposed to guide the length and degree of sick leave, we found no association between the two. We found, however, that the diagnoses made in the structured psychiatric interviews were associated with the length and degree of sick leave. Patients who fulfilled the M.I.N.I. criteria for ongoing depression had significantly fewer net sick leave days than those who did not. Additionally, few patients in either region in the current study had sick-leave certificate diagnoses of anxiety disorders, which suggests that the GPs were following recommendations that short and preferably no sick leave should be given to patients with anxiety disorders (52). Finally, the structured psychiatric interviews showed that people with adjustment disorder had the longest sick leave. This is in accordance with Swedish recommendations, which state that long sick leave may be necessary for these patients (52).

More severely ill patients received longer sick leave, which is in keeping with national guidelines (52). In all groups, participants who scored high on KEDS and/or MADRS-S had longer net sick leave than those who had low scores on these instruments. The same pattern has been found in previous studies $(1,16$, $29,34,35,53)$, which suggests that symptom severity may be the factor with the greatest influence on length of sick leave. 


\section{Limitations and strengths}

This study had a number of limitations. One was that differences in recruitment in the regions of Stockholm and Västra Götaland led to study populations that differed in age, educational level, and treatment with antidepressants. In Stockholm, participants were recruited primarily via invitations from the Swedish Social Insurance Agency. Approximately $10 \%$ of those contacted by letter responded that they were interested in participating, which means that this was a highly self-selected group. Additional participants were recruited via advertisements in the press, which may have resulted in another highly self-selected group. In the region of Västra Götaland, rehabilitation coordinators at primary health care centers asked patients who were on sick leave to participate in the study; $21 \%$ agreed to participate, and these people may also have differed from those who declined to participate.

A further limitation was the delay between the sick leave diagnoses and the structured psychiatric interviews. As noted previously, common mental disorders seem to overlap and affect one another over time $(1,3,29,32,45-47,54)$. It is possible that our results would have differed if all the structured psychiatric interviews had been conducted as part of or immediately after the sick-leave certificate diagnosis.

Finally, our study did not measure self-rated anxiety symptoms, which means that we were not able to compare anxiety symptoms in our study population with length of sick leave. In at least one other study, symptoms of anxiety were the most important predictor of length of sick leave (29).

A strength of this study was that the assessments with structured psychiatric interviews and symptom severity scales were performed by assessors other than the clinicians who performed the sick leave certification. This may have diminished assessment bias. Additionally, the study population was drawn from two regions of Sweden and included both rural and urban areas and areas of varying socioeconomic status, which could increase generalizability.

\section{Conclusion}

Many patients with sick-leave certificate diagnoses of adjustment and anxiety disorders had ongoing depression, which likely reflects the overlapping and dynamic nature of common mental disorders. There was no difference in sick leave duration by the diagnoses on sick-leave certificates, possibly reflecting the rarity of structured psychiatric diagnoses for mental disorders in primary care. However, diagnoses made in structured psychiatric interviews and the severity of patients' symptoms were associated with net sick 
leave, meaning that regardless of the diagnoses on the sick-leave certificates, overall, the length and degree of sick leave prescribed by GPs were appropriate.

\section{Abbreviations}

ACT, acceptance and commitment therapy

DSM, Diagnostic and Statistical Manual

GAD, generalized anxiety disorder

GP, general practitioner

ICD, International Classification of Diseases

KEDS, Karolinska Exhaustion Disorder Scale

M.I.N.I., MINI International Neuropsychiatric Interview

MADRS-S, Montgomery-Asberg Depression Rating Scale - self-rating version

$\mathrm{RR}$, rate ratio

SD, standard deviation

s-ED, Self-rated Stress-Related Exhaustion Disorder Instrument

\section{Declarations}

Ethics approval and consent to participate: Ethical approval for this study was obtained from the Regional Ethical Review Board in Stockholm, (Dnr: 201/2109-31/5) and the Regional Ethical Review Board in Gothenburg (Dnr: 577-13, 2013-11-18). The research was conducted in accordance with the World Medical Association Declaration of Helsinki of 1975, as revised in 1983.

Consent for publication: Not applicable.

Availability of data and materials: The data used in these analyses were gathered for the Return to Work: Promoting Health and Productivity in Workers With Common Mental Disorders (SAFARI) Study, ClinicalTrials.gov Identifier: NCT01805583. For information about data availability and to contact the party responsible for the study in the region of Stockholm, see ClinicalTrials.gov, and for Västra Götaland, see https://www.researchweb.org/info/index.php/vgr/project/207801.

Competing interests: The authors declare that they have no competing interests. 
Funding: The SAFARI study was funded by grants from Stockholm County, Region Västra Götaland, and the Swedish Social Insurance Agency. These funding bodies played no role in the design of the study; the collection, analysis, and interpretation of data; or in writing the manuscript.

Authors' contributions: The study was conducted as part of SWH's doctoral project. The data used in the study were gathered as part of the SAFARI study. AN, CB, and JW supervised the work. SWH analyzed the data and prepared the draft manuscript with the support of all the other authors. All the authors approved the final manuscript.

Acknowledgements: We thank scientific editor Kimberly Kane of Region Stockholm for English-language editing assistance.

\section{References}

1. Knudsen AK, Harvey SB, Mykletun A, Overland S. Common mental disorders and long-term sickness absence in a general working population. The Hordaland Health Study. Acta Psychiatr Scand. 2013;127(4):287-97.

2. The Swedish Social Insurance Agency. Sick leave in psychiatric diagnoses - a study of the Swedish population aged 16 - 64 years. Stockholm, Sweden: The Swedish Social Insurance Agency, 2014.

3. Bijl RV, Ravelli A. Psychiatric morbidity, service use, and need for care in the general population: results of The Netherlands Mental Health Survey and Incidence Study. American journal of public health. 2000;90(4):602-7.

4. World Health Organisation. Depression and Other Common Mental Disorders: Global Health Estimates. Geneva, Switzerland: World Health Organization, 2017.

5. Beemsterboer W, Stewart R, Groothoff J, Nijhuis F. The influence of sick leave frequency determinants on homogeneous groups in two socio-economically comparable, but socio-culturally different regions in The Netherlands. Central European journal of public health. 2008;16(4):151-60.

6. The Swedish Social Insurance Agency. Sjukfrånvarons utveckling 2018 Stockholm, Sweden: The Swedish Social Insurance Agency, 2018 Contract No.: Social Insurance Report 2018:2.

7. Lidwall U, Bill S, Palmer E, Olsson Bohlin C. Mental disorder sick leave in Sweden: A population study. Sweden2018. 1-14 p.

8. Wedegaertner F, Arnhold-Kerri S, Sittaro NA, Bleich S, Geyer S, Lee WE. Depression- and anxietyrelated sick leave and the risk of permanent disability and mortality in the working population in Germany: a cohort study. BMC public health. 2013;13:145.

9. WHO. Methods and data sources for global burden of disease estimates 2000-2011. . Geneva: 2013.

10. Ansseau M, Dierick M, Buntinkx F, Cnockaert P, De Smedt J, Van Den Haute M, et al. High prevalence of mental disorders in primary care. J Affect Disorders. 2004;78(1):49-55. 
11. Grandes G, Montoya I, Arietaleanizbeaskoa MS, Arce V, Sanchez A, Group MAS. The burden of mental disorders in primary care. European psychiatry : the journal of the Association of European Psychiatrists. 2011;26(7):428-35.

12. Toft T, Fink P, Oernboel E, Christensen K, Frostholm L, Olesen F. Mental disorders in primary care: prevalence and co-morbidity among disorders. results from the functional illness in primary care (FIP) study. Psychological medicine. 2005;35(8):1175-84.

13. Semaan W, Hergueta T, Bloch J, Charpak Y, Duburcq A, Le Guern ME, et al. [Cross-sectional study of the prevalence of adjustment disorder with anxiety in general practice]. L'Encephale. 2001;27(3):23844.

14. Solberg LI, Trangle MA, Wineman AP. Follow-up and follow-through of depressed patients in primary care: the critical missing components of quality care. The Journal of the American Board of Family Practice. 2005;18(6):520-7.

15. Alexanderson K AP, Hansson T, Hensing G, Jensen I, Maastekaasa A, et al. Sjukskrivning orsaker,konsekvenser och praxis. En systematisk litteraturöversikt. Stockholm, Sweden: Swedish Council on Health Technology Assessment, 2003 Contract No.: ISBN: 91-87890-89-5

16. de Vries H, Fishta A, Weikert B, Rodriguez Sanchez A, Wegewitz U. Determinants of Sickness Absence and Return to Work Among Employees with Common Mental Disorders: A Scoping Review. Journal of occupational rehabilitation. 2018;28(3):393-417.

17. Muschalla $B$, Linden $M$. Workplace phobia, workplace problems, and work ability among primary care patients with chronic mental disorders. Journal of the American Board of Family Medicine : JABFM. 2014;27(4):486-94.

18. Balestrieri M, Baldacci S, Bellomo A, Bellantuono C, Conti L, Perugi G, et al. Clinical vs. structured interview on anxiety and affective disorders by primary care physicians. understanding diagnostic discordance. Epidemiologia e psichiatria sociale. 2007;16(2):144-51.

19. Gilbody S, Sheldon T, House A. Screening and case-finding instruments for depression: a metaanalysis. CMAJ. 2008;178.

20. Kiessling A, Arrelov B, Larsson A, Henriksson P. Quality of medical certificates issued in long-term sick leave or disability in relation to patient characteristics and delivery of health care. Scandinavian journal of public health. 2013;41(4):412-20.

21. Swedish Council on Health Technology Assessment. Diagnostik och uppföljning av förstämningssyndrom. En systematisk litteraturöversikt. . Stockholm, Sweden: Swedish Council on Health Technology Assessment., 2012.

22. Sheehan DV, Lecrubier Y, Sheehan KH, Amorim P, Janavs J, Weiller E, et al. The Mini-International Neuropsychiatric Interview (M.I.N.I.): the development and validation of a structured diagnostic psychiatric interview for DSM-IV and ICD-10. The Journal of clinical psychiatry. 1998;59 Suppl 20:2233;quiz 4-57. 
23. Zimmerman M MTA, Stanton K. The severity of psychiatric disorders. World Psychiatry 2018;2018;17:258-75

24. Beemsterboer W, Stewart R, Groothoff J, Nijhuis F. A literature review on sick leave determinants (1984-2004). International journal of occupational medicine and environmental health. 2009;22(2):169-79.

25. Bekker MH, Rutte CG, van Rijswijk K. Sickness absence: A gender-focused review. Psychology, health \& medicine. 2009;14(4):405-18.

26. Duijts SF, Kant I, Swaen GM, van den Brandt PA, Zeegers MP. A meta-analysis of observational studies identifies predictors of sickness absence. Journal of clinical epidemiology. 2007;60(11):1105-15.

27. Holmgren K, Fjallstrom-Lundgren M, Hensing G. Early identification of work-related stress predicted sickness absence in employed women with musculoskeletal or mental disorders: a prospective, longitudinal study in a primary health care setting. Disability and rehabilitation. 2013;35(5):418-26.

28. Krause N, Frank JW, Dasinger LK, Sullivan TJ, Sinclair SJ. Determinants of duration of disability and return-to-work after work-related injury and illness: challenges for future research. American journal of industrial medicine. 2001;40(4):464-84.

29. Schneider A, Hilbert S, Hamann J, Skadsem S, Glaser J, Lowe B, et al. The Implications of Psychological Symptoms for Length of Sick Leave. Deutsches Arzteblatt international. 2017;114(17):291-7.

30. Terluin B, van Rhenen W, Anema JR, Taris TW. Psychological symptoms and subsequent sickness absence. International archives of occupational and environmental health. 2011;84(7):825-37.

31. Werner EL, Cote P. Low back pain and determinants of sickness absence. The European journal of general practice. 2009;15(2):74-9.

32. Wiegner L, Hange D, Bjorkelund C, Ahlborg G, Jr. Prevalence of perceived stress and associations to symptoms of exhaustion, depression and anxiety in a working age population seeking primary care-an observational study. BMC family practice. 2015;16:38.

33. Starzmann K, Hjerpe P, Dalemo S, Ohlsson H, Bjorkelund C, Bengtsson Bostrom K. Diagnoses have the greatest impact on variation in sick-leave certification rate among primary-care patients in Sweden: A multilevel analysis including patient, physician and primary health-care centre levels. Scandinavian journal of public health. 2015;43(7):704-12.

34. Roelen CA, Hoedeman R, van Rhenen W, Groothoff JW, van der Klink JJ, Bultmann U. Mental health symptoms as prognostic risk markers of all-cause and psychiatric sickness absence in office workers. European journal of public health. 2014;24(1):101-5.

35. Glise K, Hadzibajramovic E, Jonsdottir IH, Ahlborg G, Jr. Self-reported exhaustion: a possible indicator of reduced work ability and increased risk of sickness absence among human service workers. International archives of occupational and environmental health. 2010;83(5):511-20. 
36. Rehabiliteringsnätverket. SAFARI - psykisk ohälsa. Sweden: The Rehabilitation Network in collaboration with the Swedish Social Insurance Agency and the regions of Stockholm, Västra Götaland, and Västmanland, April 2017. Report No.

37. Finnes A, Ghaderi A, Dahl J, Nager A, Enebrink P. Randomized controlled trial of acceptance and commitment therapy and a workplace intervention for sickness absence due to mental disorders. Journal of occupational health psychology. 2019;24(1):198-212.

38. Skoglund I, Bjorkelund C, Svenningsson I, Petersson EL, Augustsson P, Nejati S, et al. Influence of antidepressant therapy on sick leave in primary care: ADAS, a comparative observational study. Heliyon. 2019;5(1):e01101.

39. World Health Organisation. ICD-10, the ICD-10 Classification of Mental and Behavioural Disorders: Diagnostic Criteria for Research. Geneva, Switzerland: World Health Organization 1993.

40. American Psychiatric Association. Quick reference to the Diagnostic and Statistical Manual of Mental Disorders, Fourth Edition (DSM IV). Washington D.C.1994.

41. Svanborg P, Asberg M. A new self-rating scale for depression and anxiety states based on the comprehensive psychopathological rating scale. Acta Psychiatr Scand. 1994;89.

42. Beser A, Sorjonen K, Wahlberg K, Peterson U, Nygren A, Asberg M. Construction and evaluation of a self rating scale for stress-induced exhaustion disorder, the Karolinska Exhaustion Disorder Scale. Scandinavian journal of psychology. 2014;55(1):72-82.

43. Saboonchi F, Perski A, Grossi G. Validation of Karolinska Exhaustion Scale: psychometric properties of a measure of exhaustion syndrome. Scandinavian journal of caring sciences. 2013;27(4):1010-7.

44. Hilbe JM. Negative binomial regression (2nd ed.). New York, NY, US: Cambridge University Press; 2011.

45. Roca M, Gill M, Garcia-Garcia M, Salva J, Ylves M, Garcia Campayo J. Prevalence and comorbidity of common mental disorders in primary care. J Affect Disord. 2009;119.

46. Hanel G, Henningsen P, Herzog W, Sauer N, Schaefert R, Szecsenyi J, et al. Depression, anxiety, and somatoform disorders: vague or distinct categories in primary care? Results from a large crosssectional study. Journal of psychosomatic research. 2009;67(3):189-97.

47. Combs H, Markman J. Anxiety disorders in primary care. The Medical clinics of North America. 2014;98(5):1007-23.

48. Bener A, Al-Kazaz M, Ftouni D, Al-Harthy M, Dafeeah EE. Diagnostic overlap of depressive, anxiety, stress and somatoform disorders in primary care. Asia-Pacific psychiatry : official journal of the Pacific Rim College of Psychiatrists. 2013;5(1):E29-38.

49. Hakanen JJ, Schaufeli WB. Do burnout and work engagement predict depressive symptoms and life satisfaction? A three-wave seven-year prospective study. J Affect Disord. 2012;141(2-3):415-24.

50. Swedish National Audit Office. Assessment of working capacity in cases of mental ill health - a process with great challenges. Stockholm, Sweden: Swedish National Audit Office, 20184 MAY 2018 Report No.: Contract No.: REPORT NUMBER: RIR 2018:11. 
51. Pettersson A, Modin S, Wahlstrom R, Af Winklerfelt Hammarberg S, Krakau I. The Mini-International Neuropsychiatric Interview is useful and well accepted as part of the clinical assessment for depression and anxiety in primary care: a mixed-methods study. BMC Fam Pract. 2018;19(1):19.

52. Swedish National Board of Health and Wellfare. Försäkringsmedicinskt beslutsstöd Sweden: National Board of Health and Wellfare; 2017.

53. Kristiansen J, Friborg MK, Eller N, Brandt LPA, Glasscock DJ, Pihl-Thingvad J, et al. Comparison of exhaustion symptoms in patients with stress-related and other psychiatric and somatic diagnoses. Bmc Psychiatry. 2019;19(1):84.

54. Grossi G, Perski A, Osika W, Savic I. Stress-related exhaustion disorder-clinical manifestation of burnout? A review of assessment methods, sleep impairments, cognitive disturbances, and neurobiological and physiological changes in clinical burnout. Scandinavian journal of psychology. 2015;56(6):626-36.

\section{Figures}


Figure 1. Recruitment of the two substudy populations

\section{Region of Stockholm}

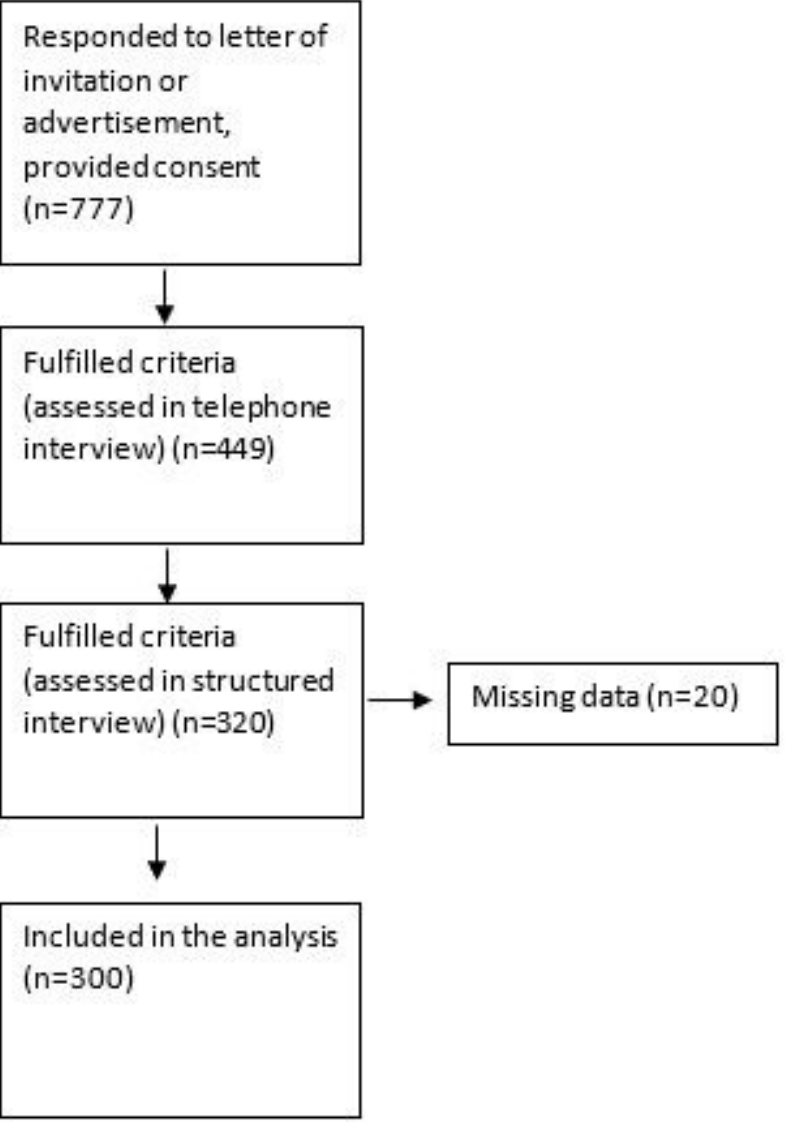

\section{Region of Västra Götaland}

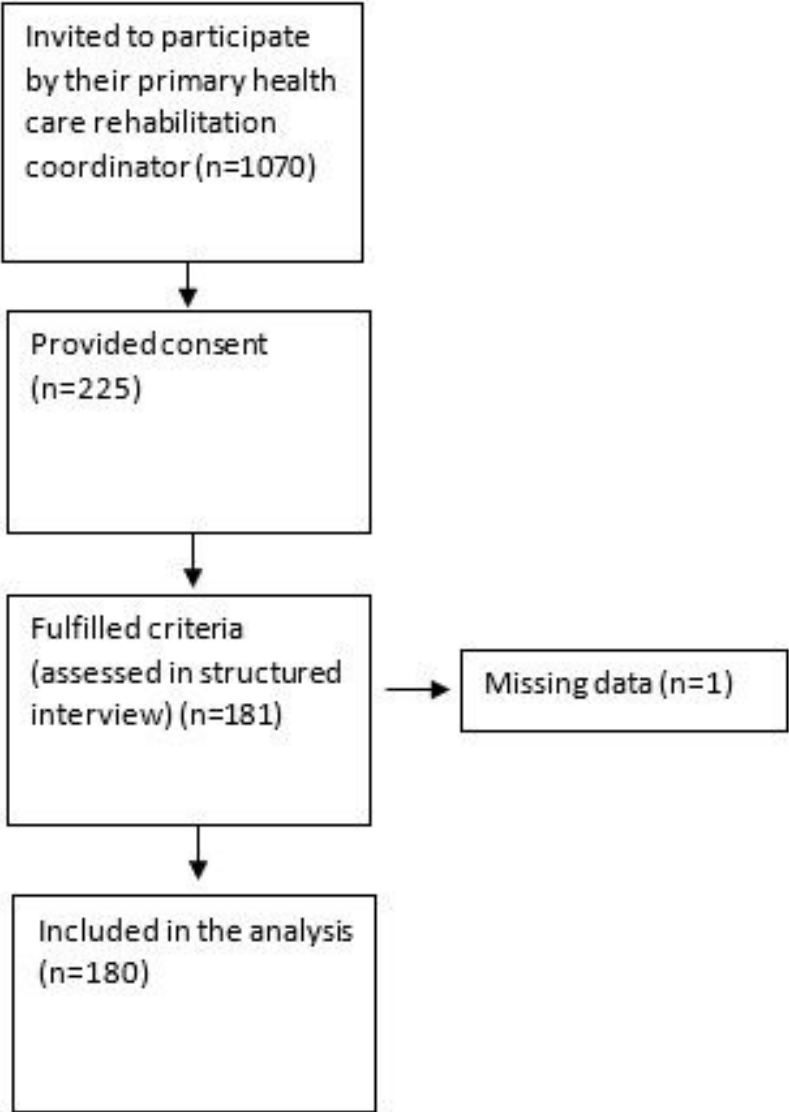

Figure 1

Recruitment of the two substudy populations 


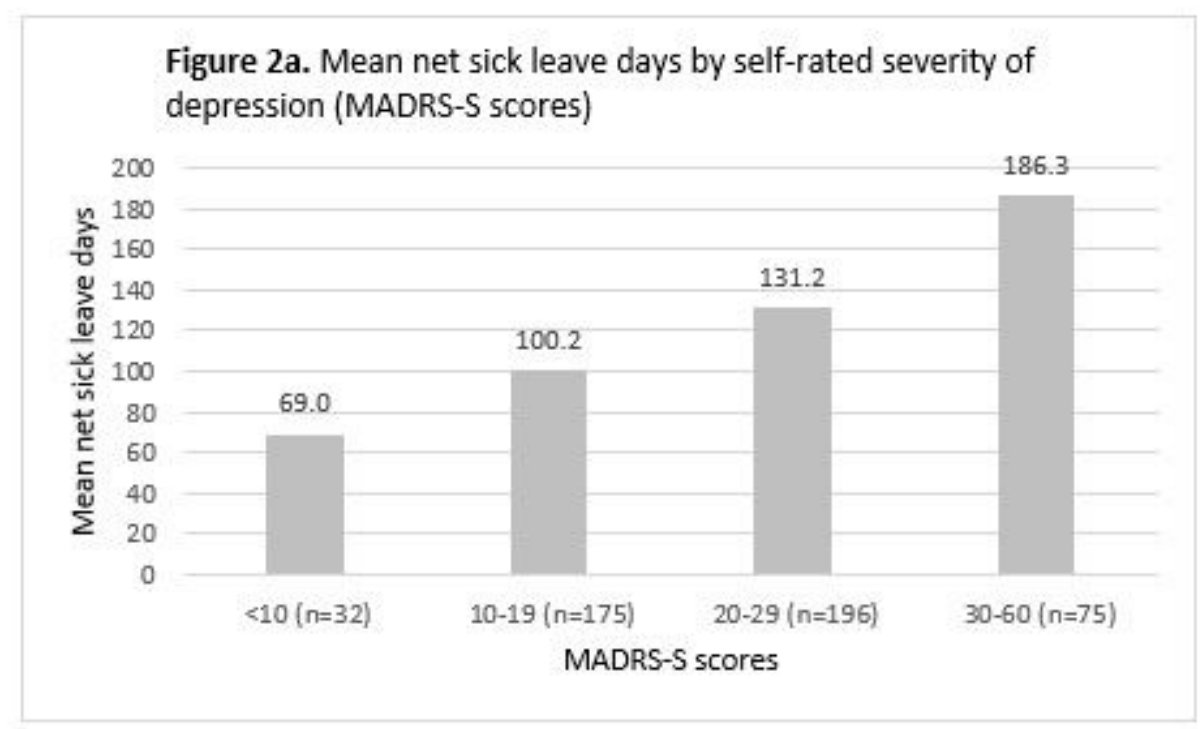

Abbreviations: MADRS-S, Montgomery-Asberg Depression Rating Scale - self-rating version

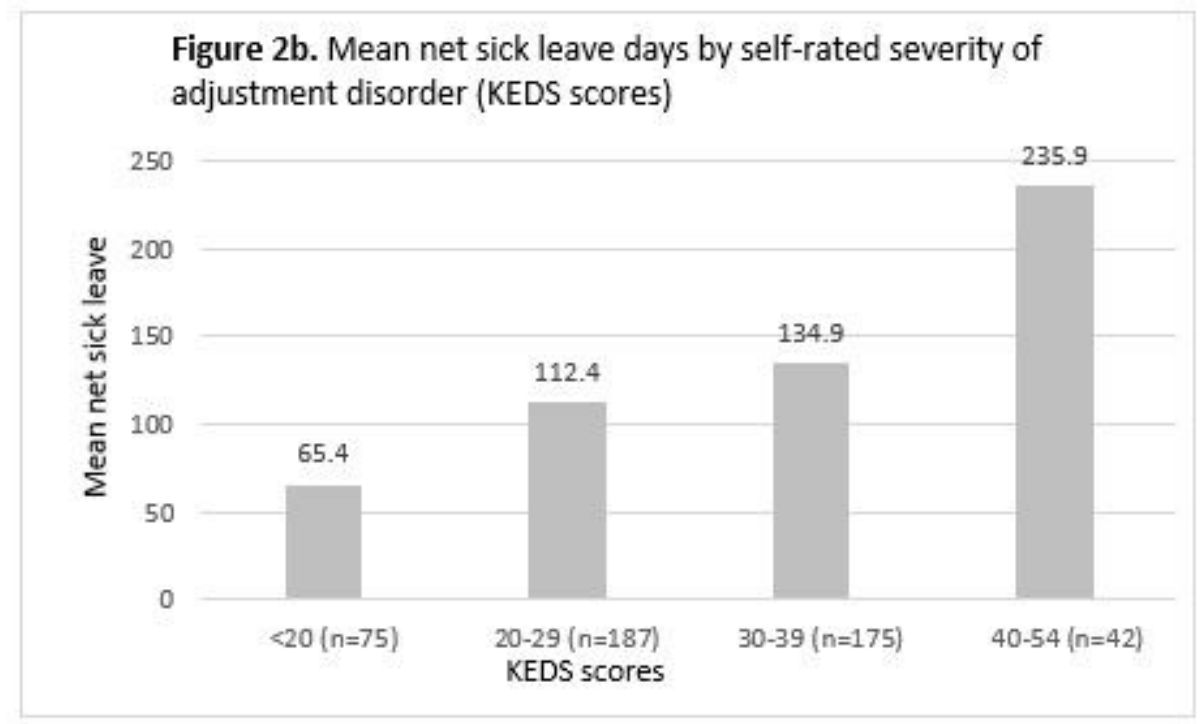

Abbreviations: KEDS, Karolinska Exhaustion Disorder Scale

\section{Figure 2}

2a. Mean net sick leave days by self-rated severity of depression (MADRS-S scores) Abbreviations: MADRS-S, Montgomery-Asberg Depression Rating Scale - self-rating version b. Mean net sick leave days by self-rated severity of adjustment disorder (KEDS scores) Abbreviations: KEDS, Karolinska Exhaustion Disorder Scale 